Abstract-Black Sea Bass (Centropristis striata) in the mid-Atlantic Bight undertake seasonal cross-shelf movements to occupy inshore rocky reefs and hardbottom habitats between spring and fall. Shelf-wide migrations of this stock are well documented, but movements and home ranges of fish during their inshore residency period have not been described. We tagged 122 Black Sea Bass with acoustic transmitters at a mid-Atlantic reef to estimate home-range size and factors that influence movements ( $>400 \mathrm{~m})$ at a $46.1-\mathrm{km}^{2}$ study site between May and November 2003. Activity of Black Sea Bass was greatest and most consistent during summer but declined rapidly in September as water temperatures at the bottom of the seafloor increased on the inner shelf. Black Sea Bass maintained relatively large home ranges that were fish-size invariant but highly variable (13.7-736.4 ha), underscoring the importance of large sample sizes in examination of population-level characteristics of mobile species with complex social interactions. On the basis of observed variations in movement patterns and the size of home ranges, we postulate the existence of groups of conspecifics that exhibit similar space-use behaviors. The group of males released earlier in the tagging period used larger home ranges than the group of males released later in our study. In addition, mean activity levels and the probability of movement among acoustic stations varied among groups of fish in a complex manner that depended on sex. These differences in movement behaviors may increase the vulnerability of male fish to passive fishing gears, further exacerbating variation in exploitation rates for this species among reefs.

Manuscript submitted 21 January 2013. Manuscript accepted 11 December 2013. Fish. Bull 112:82-97 (2014).

doi: 10.7755/FB.112.1.5

The views and opinions expressed or implied in this article are those of the author (or authors) and do not necesarily reflect the position of the National Marine Fisheries Service, NOAA.

\title{
Home range and seasonal movements of Black Sea Bass (Centropristis striata) during their inshore residency at a reef in the mid-Atlantic Bight
}

\author{
Mary C. Fabrizio (contact author) ${ }^{1}$ \\ John P. Manderson'2 \\ Jeffrey P. Pessutti² \\ Email address for contact author: mfabrizio@vims.edu \\ 1 Virginia Institute of Marine Science \\ College of William \& Mary \\ P.O. Box 1346 \\ Gloucester Point, Virginia 23062 \\ 2 James J. Howard Marine Sciences Laboratory \\ Northeast Fisheries Science Center \\ National Marine Fisheries Service, NOAA \\ 74 Magruder Road \\ Highlands, New Jersey 07732
}

The vulnerability of marine and estuarine species to capture by recreational and commercial fisheries is enhanced when individuals aggregate during a predictable time of year. For example, the spring spawning migrations of anadromous fishes, such as American Shad (Alosa sapidissima) and Striped Bass (Morone saxatilis), historically fueled productive fisheries along the U.S. Atlantic coast (Limburg and Waldman, 2009). In the mid-Atlantic region, fishes that use inshore reefs as feeding and spawning areas between spring and fall also may increase their vulnerability to fishing gear because individuals are associated with welldefined habitat features that may be targeted by fishing operations.

Management of species that exhibit aggregation behaviors often is dependent upon spatially explicit regulations that aim to protect differentially vulnerable individuals. For instance, the harvest of blue crabs is prohibited in the lower Chesapeake Bay and the adjacent coastal ocean from May through mid-September to protect spawning females (Miller et al., $\left.2011^{1}\right)$. Similarly, marine protect-

\footnotetext{
${ }^{1}$ Miller, T. J., M. J. Wilberg, A. R. Colton, G. R. Davis, A. Sharov, R. N. Lipcius,
}

ed areas and reserves may be used to reduce or eliminate fishing mortality on depleted stocks (e.g., the sea scallop fishery in the North Atlantic; Murawski et al., 2000). For such area closures and related spatial management approaches, many of the individuals from the target population area are assumed to use protected areas and their movements away from these areas are assumed to be minimal and temporary. Therefore, to achieve management goals, protected areas or networks of reserves should be large enough to sufficiently encompass the home ranges of individuals of the target populations (Moffitt et al., 2009).

Home range and movements of mobile species can be assessed with acoustic telemetry (e.g., Dawson and Starr, 2009; Douglas et al., 2009; Meyer et al., 2009; Farmer and Ault, 2011; Knip et al., 2012). Although such techniques provide temporally

G. M. Ralph, E. G. Johnson, and A. G. Kaufman. 2011. Stock assessment of the blue crab in Chesapeake Bay. Univ. Maryland Center for Environmental Science, Technical Report Series TS-614-11, 203 p. [Available at http://www.cio. noaa.gov/Policy_Programs/prplans/ ID180_Chesapeake_Blue_Crab_Assessment.document_final_approved.pdf.] 
intensive information, many acoustic studies of the home ranges of fishes have been conducted on relatively small spatial scales (hundreds of meters to a few kilometers) or during brief periods of time (days to weeks) with few fish (typically 15 or less). These spatial and temporal scales of study may be sufficient for elucidating the size of the home range of relatively sedentary fishes that inhabit restricted areas, such as coral reefs. However, recent work indicates that estimates of home range may be larger when habitat use of a target fish is monitored over larger spatial scales and over longer time periods (Farmer and Ault, 2011). Furthermore, because movement behaviors may vary among individuals, large sample sizes could improve our understanding of the size of the home range for a given species.

Predictable seasonal aggregations of Black Sea Bass (Centropristis striata) occur in nearshore areas of the mid-Atlantic region. Between spring and fall, populations of this species are exploited by recreational hookand-line fisheries, as well as by commercial pot fisheries (Shepherd and Terceiro, 1994). The Black Sea Bass is a demersal species in the family Serranidae, and individuals are commonly found to associate with hardbottom structures, such as reefs, rock outcroppings, and wrecks (Steimle and Zetlin, 2000; Fabrizio et al., 2013). Along the Atlantic coast, individual fish undertake annual migrations to the middle- and outer-continental shelf during winter (Musick and Mercer, 1977; Moser and Shepherd, 2009); in the spring, Black Sea Bass migrate inshore, often returning to areas occupied in the previous year (Moser and Shepherd, 2009). Timing of these seasonal cross-shelf migrations varies with latitude, but fish movements are believed to be in response to changes in water temperature at the bottom of the seafloor and in photoperiod (Moser and Shepherd, 2009; Fabrizio et al., 2013). Black Sea Bass are protogynous hermaphrodites, and larger fish (>450 $\mathrm{mm}$ total length [TL]) tend to be predominantly male (NEFSC ${ }^{2}$ ). During the spawning season, mature (dominant) males can be identified by a bright blue hump on the nape. However, external morphological differentiation among subordinate males, transitional males, and females is not possible for this species $\left(\mathrm{NEFSC}^{2}\right.$ ). Because harvests are directed at larger fish (>250 $\mathrm{mm}$ TL), mature males tend to experience higher fishing-induced mortality rates than females and less developed males.

Spatial regulations are not used currently to manage Black Sea Bass, but a coastwide tagging study has indicated that exploitation rates among individual reefs in the mid-Atlantic region may be highly variable (NEFSC ${ }^{3}$ ). Furthermore, because Black Sea Bass

\footnotetext{
2 NEFSC (Northeast Fisheries Science Center). 2012. 53rd northeast regional stock assessment workshop (53rdSAW) assessment report. Northeast Fish. Sci. Cent. Ref. Doc. 12 05, 559 p. [Available from National Marine Fisheries Service, 166 Water St., Woods Hole, MA 02543-1026.

${ }^{3}$ NEFSC (Northeast Fisheries Science Center). 2004. 39 ${ }^{\text {th }}$ northeast regional stock assessment workshop (39 ${ }^{\text {th }}$ SAW) as-
}

spawn in summer while resident at these reefs $(\mathrm{Mu}-$ sick and Mercer, 1977), the effect of localized fishing on the future production of this stock is unknown. Moser and Shepherd (2009) indicate that the individuals of the mid-Atlantic stock off the coast of New Jersey are fairly sedentary while resident in inshore waters; because they inferred these movements from a conventional tagging study, movements that occurred between the time of capture and subsequent recapture could not be discerned. Data from conventional tagging studies cannot be used to resolve movements at fine temporal scales (e.g., hours to days), although it is known that many fishes display regular activity patterns that may change seasonally (Reebs, 2002).

In this study, we used acoustic tagging to investigate the home range and seasonal movements of Black Sea Bass during their inshore residency at a temperate reef in the mid-Atlantic Bight. We examined the effect of fish size, sex, and duration of occupancy on size of home ranges, and we explored the effects of sex and time on movement and activity levels of individual fish. We considered a range of temporal scales, from diel to those occurring over several months, to describe movements of fish on the reef.

\section{Materials and methods}

\section{Study site and acoustic grid}

We established a $46.1-\mathrm{km}^{2}$ grid that consisted of 72 moored receivers (model VR2, Vemco, Ltd., ${ }^{4}$ Bedford, Nova Scotia, Canada) at 72 acoustic stations within a study site about $6.5 \mathrm{~km}$ off the coast of New Jersey (Fig. 1, A and B). In April 2003, adjacent receivers were placed $800 \mathrm{~m}$ apart because a range test conducted earlier at this site indicated that the effective detection range of deployed receivers was about $400 \mathrm{~m}$ (Fabrizio et al., 2013). Sediments at this site ranged from finegrain mud to coarse-grain material, such as sand, gravel, and rocks (Lathrop et al., 2006); rock outcrops were observed near the center of this site $\left(\right.$ Butman $\left.^{5}\right)$. Historically, this area comprised a number of "dump sites" used to dispose of dredged materials from the Port of New York and New Jersey, as well as of construction material and other refuse. In 1997 , the $53.8-\mathrm{km}^{2}$ area that surrounds the old dump sites was designated a Historic Area Remediation Site (HARS). This site is used by Black Sea Bass during their inshore residency

sessment summary report. Northeast Fish. Sci. Cent. Ref. Doc. 04-10a, 16 p. [Available from National Marine Fisheries Service, 166 Water St., Woods Hole, MA 02543-1026.]

4 Mention of trade names or commercial companies is for identification purposes only and does not imply endorsement by the National Marine Fisheries Service, NOAA.

5 Butman, B. 2002. Mapping the seafloor of the Historic Area Remediation Site (HARS) offshore of New York City. U.S. Geological Survey Fact Sheet 001-02, 4 p. [Available at http://pubs.usgs.gov/fs/2002/fs001-02/fs001-02.pdf.] 

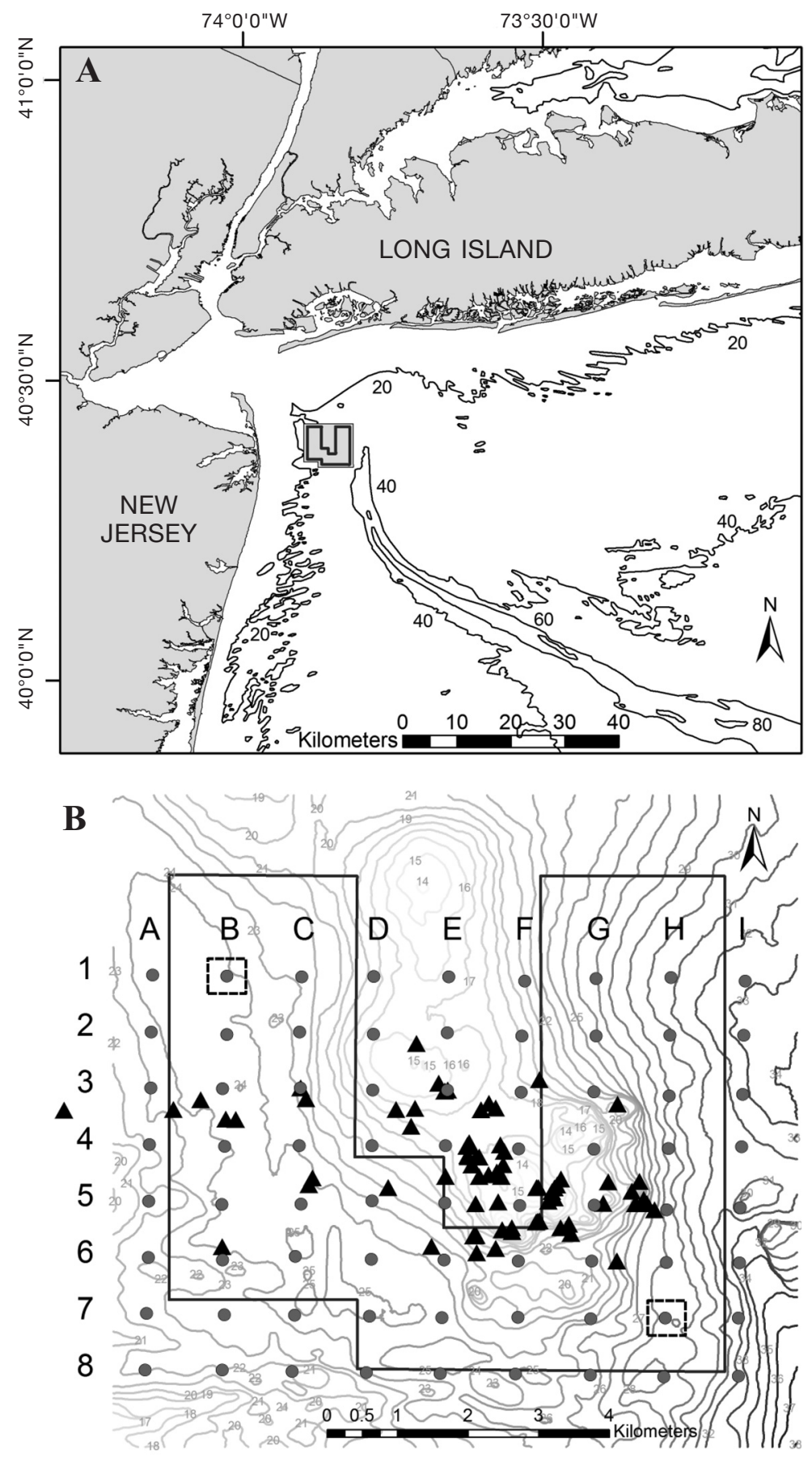

Figure 1

(A) Location and bathymetry (20-m isobaths) of the Historic Area Remediation Site (HARS) in the mid-Atlantic Bight. (B) Grid of stations where 72 acoustic receivers were deployed (filled circles) and locations where Black Sea Bass (Centropristis striata) were released (filled triangles) at the HARS (solid black line) between May and July 2003. The contour lines are 1-m isobaths and the acoustic grid encompasses $46.1 \mathrm{~km}^{2}$ of the HARS. Column (A-I) and row (1-8) designations represent naming conventions for acoustic stations. Dashed squares at stations B1 and H7 indicate locations of sensors used to measure temperature and salinity at the bottom of the seafloor.
(Fabrizio et al., 2013), and this population supports recreational fisheries in New York and New Jersey.

At each acoustic station, we deployed an array that consisted of a 400-lb pyramidal anchor, an acoustic receiver (VR2), and a shallow-water release encased in a positively buoyant canister (SWR Pop-Up recovery system, ORE Offshore, West Wareham, MA). To provide maximum horizontal sensitivity (Clements et al., 2005), receivers were oriented vertically. Pop-up buoys facilitated retrieval of receivers during fall 2003 and in summer 2004. Temperature and salinity sensors (SBE 16 SeaCAT Recorder, Sea-Bird Electronics, Inc., Bellevue, WA) were deployed at stations $\mathrm{B} 1$ and $\mathrm{H} 7$ (for locations of these stations, see Fig. 1B), suspended about $3 \mathrm{~m}$ above the substratum; these sensors recorded data every $30 \mathrm{~min}$. We used mean daily temperature, mean daily salinity, and mean daily difference in temperature and salinity between the 2 stations as measures of environmental conditions at the site. In this study, we analyzed acoustic data collected from 30 May to 14 December 2003 to estimate home ranges and describe movements of Black Sea Bass in the mid-Atlantic Bight during their inshore residency period.

\section{Implantation of transmitters}

We captured 129 Black Sea Bass at various locations within the acoustic grid at the HARS between 30 May and 16 July 2003 and implanted them with acoustic transmitters before release near the location of capture (Fig. 1B). Fish identification was made on the basis of Collette and Klein-MacPhee (2002). Black Sea Bass were captured by either hook-and-line angling $(n=45)$ or commercial fish traps $(n=84)$ that were allowed to soak at the site for 1-3 nights before retrieval. Upon capture, all fish were immediately placed into onboard holding tanks supplied with flow-through seawater. Although swim bladder inflation was evident in most fish, neither deflation with a hypodermic needle (Collins et al., 1999) nor "hanging" the traps at a depth of $10 \mathrm{~m}$ (Neufeld and Spence, 2004) completely eliminated decompression trauma. Before surgery, we anesthetized fish with $80 \mathrm{mg} / \mathrm{L}$ Aqui-S (Aqui-S New Zealand Ltd., Lower Hutt, New Zealand); this concentration allowed us to induce anesthesia in reasonably short times (mean, $3.3 \mathrm{~min}$; range, 1.1-7.7 $\min ; n=127$ [induction time was not recorded for 2 fish]). 
Transmitters (V8SC-2H, Vemco, Ltd., Bedford, Nova Scotia, Canada) were implanted in 129 anesthetized Black Sea Bass (mean size, 307 mm TL; range, 220$431 \mathrm{~mm}$ TL; $n=129$ ) at the study site using surgical techniques described in Fabrizio and Pessutti (2007). Dummy transmitters of the same size (30 $\mathrm{mm}$ long and $9 \mathrm{~mm}$ in diameter), shape, and weight ( $5 \mathrm{~g}$ in air, $3.1 \mathrm{~g}$ in water) had $100 \%$ retention rates in laboratory-held Black Sea Bass (Fabrizio and Pessutti, 2007). Transmitters emitted a coded acoustic signal at $69 \mathrm{kHz}$ every $210 \mathrm{~s}$ on average (signal delay varied randomly between 120 and $300 \mathrm{~s}$ ) and had a battery life of $384 \mathrm{~d}$. Surgery time averaged $4.1 \mathrm{~min}$ (range, 2.0-11.7 min; $n=128$ [surgery time not recorded for $1 \mathrm{fish}$ ); immediately after surgery, the length and sex of each fish was recorded. Sex determination was limited to classification of fish as either male $(n=34)$ or fish of unknown sex $(n=88)$; the latter group included females, subordinate males, and transitional males.

Sizes of the 2 groups overlapped: males ranged between 270 and $431 \mathrm{~mm}$ TL, with a mean of $343.5 \mathrm{~mm}$ TL ( \pm standard error of the mean [SE] 6.32) and fish of unknown sex ranged between 220 and $395 \mathrm{~mm}$ TL, with a mean of $292.6 \mathrm{~mm}$ TL (SE 4.50). We used ram ventilation to resuscitate fish in a flow-through seawater tank onboard the vessel and released fish within the study site as soon as fish were able to swim forcefully downward. All procedures were conducted at a mean temperature of $17.8^{\circ} \mathrm{C}$ (range: $13.6-24.2^{\circ} \mathrm{C}$ ) and 27.1 psu salinity (range: $22.1-31.0 \mathrm{psu}$ ). Of the $129 \mathrm{im}-$ planted fish, 5 carried transmitters that malfunctioned and 2 fish died within hours of release, resulting in 122 live Black Sea Bass with functioning transmitters.

\section{Home range}

Home-range area, measured in hectares (ha), was calculated for individual Black Sea Bass with the kernel density estimator. Kernel methods provide a probabilistic description of the space used by an organism and require a smoothing parameter to efficiently describe the density distribution of the individual location data (Worton, 1989). We used the bivariate normal distribution to estimate kernel home ranges with the adehabitat package in $\mathrm{R}$ ( $\mathrm{R}$ Development Core Team, 2005; Calenge, 2006). For each fish, we eliminated observations from the release date to exclude data from the period during which fish may have been recovering from surgery and excluded data from the last week of occupancy at the site to ensure that we considered only those fish that were clearly not in the process of dispersing from the study site (Fabrizio et al., 2013); as a result, 109 fish were retained for analysis of home range.

We used the $85 \%$ probability polygon to define homerange area and investigated the effect of sex on home range through the use of an analysis of covariance with fish size, duration of occupancy (days), and release date as covariates. Duration of occupancy was estimated on the basis of the total number of days that the fish was detected within the study site, and this estimate is likely a conservative one. In particular, fish captured, tagged, and released at the end of the tagging period may have previously occupied the site.

Release date was considered in the model because preliminary investigations revealed potentially significant variation in home-range size associated with this factor. The model, which contained only fixed effects, was fitted using the MIXED procedure in SAS (vers. 9.3, SAS Institute, Inc., Cary, NC), and model parameters were estimated with restricted maximum likelihood (REML) (Littell et al., 2002). Examination of residuals from an initial model run indicated heterogeneity of variance in the home-range data; we, therefore, $\log _{e}$-transformed home ranges and verified that residuals from this model supported the assumption of homogeneity of variance. To test the assumption of equality of slopes for males and fish of unknown sex, we fitted a model that included all possible 2-way interactions with sex (sex $\times$ duration of occupancy, sex $\times$ length, and sex $\times$ release date):

$$
Y_{\mathrm{ijk}}=\mu+\delta+\gamma+\alpha_{\mathrm{i}}+\beta_{\mathrm{j}}+(\alpha \delta)_{\mathrm{i}}+(\alpha \gamma)_{\mathrm{i}}+(\alpha \beta)_{\mathrm{ij}}+\varepsilon_{\mathrm{ijk}},
$$

where $Y_{\mathrm{ijk}}=$ the natural log of the home range for the $\mathrm{k}^{\text {th }}$ fish of the $\mathrm{i}^{\text {th }}$ sex released on the $\mathrm{j}^{\text {th }}$ date;

$\mu=$ the intercept;

$\delta=$ the effect of duration of occupancy (days);

$\gamma=$ the effect of fish size;

$\alpha_{i}=$ the effect of the $i^{\text {th }}$ sex;

$\beta_{j}=$ the effect of the $j^{\text {th }}$ release date; and

$\varepsilon_{\mathrm{ijk}}=$ the random unexplained error.

\section{Indices of movement}

To gauge movement of fish, we developed 2 indices. The binomial movement index allowed us to investigate factors associated with movement (e.g., are fish more likely to move during the night?), whereas the continuous activity index provided information on the extent of movements (e.g., how does activity level change in response to temperature?). The movement index indicated whether fish moved between adjacent acoustic stations during a given 3 -h interval on a given day; this index was coded " 0 " (no movement) or " 1 ."

To minimize autocorrelations among hourly observations, we considered location data during 4 time periods of each day: dawn, day, dusk, and night. Dawn and dusk periods were defined as the 3 hours centered on the beginning and end of nautical twilight (U.S. Naval Observatory, http://aa.usno.navy.mil/faq/docs/RST_defs. php); day and night were defined as the 3 -h periods midway between dawn and dusk or dusk and dawn. The movement index for each time period was calculated daily for each fish between the time of tagging and 19 November 2003; after this date, fewer than 3 fish were detected in a given time period. In this manner, 24,789 observations from 121 fish were available 
for analysis (one fish was detected at the study site for $<3 \mathrm{~h}$ and was, therefore, excluded from analysis).

The activity index was defined as the average number of times a fish moved between adjacent acoustic stations per hour during a given 3 -h time period (dawn, day, dusk, and night). This index was calculated for fish that moved at least once in a 3 -h period, and values for this index ranged between 0.33 and 9. Like the movement index, the activity index indicated movements on the scale of about $400 \mathrm{~m}$. Activity indices were calculated for each time period between the time of tagging and 6 November 2003 because observations on activity levels were not temporally consecutive after this date. As before, 121 fish contributed information; 11,843 observations were available for this index.

\section{Analysis of movement}

We used a generalized linear model to examine diel and seasonal patterns in fish movement and to estimate the probability that a fish moved as a function of sex, water temperature at the bottom of the seafloor, and salinity at the bottom of the seafloor. We did not consider effects of fish size because preliminary investigations indicated that movement did not vary with size. Time entered the model as continuous linear, quadratic, and cubic effects and corresponded to calendar day (i.e., time $=1$ on 30 May, and time $=174$ on 19 November). Quadratic time effects allow the direction of the response to change once (e.g., the response increases, reaches a maximum, and then decreases); cubic time effects are required when the direction of the response changes twice. All time factors were standardized to remove effects of collinearity; centering the data was not effective. The effects of season (summer [30 May-7 Sep] or fall [8 Sep-19 Nov]) and time period (dawn, day, dusk, and night) also were considered.

In addition to these multiscale temporal effects, we examined the effect of release group (defined according to tagging date: early June, late June, or July) because preliminary modeling indicated heterogeneity of movements for fish tagged at different times. Environmental effects were characterized by water temperature and salinity measured at the bottom of the seafloor at the study site. Specifically, we used mean bottom water temperature at station B1 and differences in mean water temperature and salinity at the bottom of the seafloor between stations $\mathrm{H} 7$ and B1; these measures were estimated for each day of the study and standardized by scaling the data with the standard deviation. These environmental factors were selected because tolerance estimates for other measures (e.g., mean temperature at station $\mathrm{H} 7$ ) indicated strong collinearity with time (tolerance values $<0.10$ ) that could not be removed through standardization or centering (Quinn and Keough, 2002).

Because movement indices $(0,1)$ were recorded daily for each fish during 4 time periods, we analyzed these data with a repeated-measures approach to address the potential correlation among observations from each fish. Furthermore, we identified individual fish nested within a time period as the subject for modeling the repeated measures. We fitted the following generalized linear model to the data:

$$
\begin{gathered}
Y_{\mathrm{jklmn}}=\mu+\beta_{\mathrm{j}}+\delta_{\mathrm{k}}+\gamma_{\mathrm{l}}+\lambda_{\mathrm{m}}+\tau_{\mathrm{n}}+\tau_{\mathrm{n}}^{2}+\tau_{\mathrm{n}}^{3}+\phi+\kappa+\alpha \\
+ \text { interactions, }
\end{gathered}
$$

where $Y_{\text {jklmn }}=$ the binomial movement index of the $\mathrm{i}^{\text {th }}$ fish of the $\mathrm{j}^{\text {th }}$ sex of the $\mathrm{k}^{\text {th }}$ tagging group in the $1^{\text {th }}$ season in the $\mathrm{m}^{\text {th }}$ time period for the $n^{\text {th }}$ day (time);

$\mu=$ the expected response (either 0 or 1 );

$\mathrm{b}_{\mathrm{j}}=$ the effect of the $\mathrm{j}^{\text {th }}$ sex;

$\delta_{\mathrm{k}}=$ the effect of the $\mathrm{k}^{\text {th }}$ tagging group;

$\gamma_{1}=$ the effect of the $1^{\text {th }}$ season;

$\lambda_{\mathrm{m}}=$ the effect of the $\mathrm{m}^{\text {th }}$ time period;

$\tau_{\mathrm{n},} \tau_{\mathrm{n}, \text { and }}^{2} \tau_{\mathrm{n}}^{3}=$ the linear, quadratic, and cubic effects of the $\mathrm{n}^{\text {th }}$ day;

$\phi=$ the effect of mean daily temperature at station B1;

$\kappa=$ the effect of the mean temperature difference between stations B1 and H7;

$\alpha=$ the effect of the mean difference in salinity between stations B1 and H7; and

interactions refers to 2- and 3-way interactions between the fixed effects.

We did not include higher-order interactions in the generalized linear model because such complexity was either unnecessary or severely reduced the precision of the estimated parameters. In this model, $Y_{\mathrm{jklmn}}$ was assumed to be distributed as a binomial. The generalized estimating equation (GEE) method was used to estimate model parameters (Liang and Zeger, 1986; Littell et al., 2002) with the GENMOD procedure in SAS (vers. 9.3).

We evaluated several covariance structures to describe the potential correlation among the binomial responses: independent, compound symmetry, autoregressive with lag 1 , and $m$-dependent (SAS User's Guide, vers. 9.3). For the $m$-dependent structure, correlations varied with the first $m$-time intervals, but were equal to 0 after the $m^{\text {th }}$ interval. Because we fitted a number of potential models, we used the information-theoretic approach to identify the most suitable model from the set of models that we considered (Burnham and Anderson, 2002).

Typically, Akaike's information criterion (AIC) is calculated from model likelihoods, and differences in model values of AIC are used to guide model selection; the model with the lowest criterion is considered best. However, GEE methods do not use likelihoods to compute model parameters; instead, quasi-likelihoods are used. For GEE models, the quasi-likelihood information criterion (QIC), which is a modification of the AIC, was used to select the covariance structure that best fits the data and to guide model selection (Pan, 2004). In 
keeping with this approach, we do not report $P$-values here but instead interpret the "importance" of factors on the basis of their contribution to the model.

\section{Analysis of activity}

We similarly modeled the effect of sex, time, release group, and environmental factors on the mean activity index of those fish that exhibited movement, but here we used a general linear mixed model (GLMM) fitted with the MIXED procedure in SAS (vers. 9.3; Littell et al., 2002). To meet the homogeneity-of-variance assumption, the activity index was $\log _{e}$ transformed. Individual fish were treated as a random factor in the model, allowing us to estimate variation among individuals. As before, we modeled the effects of the following fixed factors on the activity of fish: continuous linear, quadratic, and cubic time (standardized to eliminate collinearity), time period (dawn, day, dusk, and night), sex, season, release group, mean water temperature at station B1, and mean temperature and salinity differences between stations $\mathrm{H} 7$ and B1 (standardized). A repeated-measures approach was used here as well, with fish nested within time period as the subject. We used the following repeated-measures mixed model to fit the data:

$$
\begin{aligned}
Y_{\mathrm{i}(\mathrm{m}) \mathrm{jkln}}=\mu+ & \alpha_{\mathrm{i}(\mathrm{m})}+\beta_{\mathrm{j}}+\delta_{\mathrm{k}}+\gamma_{1}+\lambda_{\mathrm{m}}+\tau_{\mathrm{n}}+\tau_{\mathrm{n}}^{2}+\tau_{\mathrm{n}}^{3}+\phi+\kappa \\
& +\alpha+\text { interactions }+\varepsilon_{\mathrm{i}(\mathrm{m}) \mathrm{jklmn}}
\end{aligned}
$$

where $Y_{\mathrm{j}(\mathrm{m}) \mathrm{jkln}}=$ the activity index of the $\mathrm{i}^{\text {th }}$ fish of the $\mathrm{j}^{\text {th }}$ sex of the $\mathrm{k}^{\text {th }}$ tagging group in the $\mathrm{l}^{\text {th }}$ season nested in the $\mathrm{m}^{\text {th }}$ time period of the $\mathrm{n}^{\text {th }}$ day (time);

$\mu=$ the expected activity index;

$\alpha_{\mathrm{i}(\mathrm{m})}=$ the random effect of the $\mathrm{i}^{\text {th }}$ fish nested in the $\mathrm{m}^{\text {th }}$ time period;

interactions refers to 2- and 3-way interactions between the fixed effects;

$\varepsilon_{\mathrm{i}(\mathrm{m}) \mathrm{jklmn}}=$ the random unexplained error; and other terms are as defined before.

We considered 2- and 3-way interactions in this model because such interactions greatly reduced the AIC; however, inclusion of more than two 3-way interactions or higher-order interactions resulted in severe loss of precision, and such models were abandoned. With the GLMM, we assumed that the response and the random error are normally distributed and that the variance of the response is homogeneous across the levels of the factors included in the model. We modeled heterogeneity in the covariance structure among dawn, day, dusk, and night in the GLMM through the use of the group option in the MIXED procedure and specified the Kenward-Roger method for calculating degrees of freedom (Kenward and Roger, 1997). Model building followed the approach in Zuur et al. (2007) and Bolker et al. (2008): the random structure of the model (i.e., the appropriate variance-covariance structure and the importance of the random factor) was identified with REML-based estimates of AIC. Compound symmetry, autoregressive with lag 1, autoregressive moving average with lag 1, and power covariance structures (Littell et al., 2006) were used to model the correlations among the repeated responses. Next, using the random structure identified in the previous step, we calculated AIC values for models that contained different fixed effects, using maximum likelihood; those interactions that reduced AIC values were considered important and retained. Finally, REML was used to compute the final model parameters.

\section{Results}

Acoustic data were obtained from 70 of the 72 deployed receivers and most detections occurred during the summer (from 30 May to 7 September; B4 and I2 were not recovered). After September 2003, we had reduced acoustic coverage of the study area because we were unable to retrieve 12 receivers in 2004; most of these receivers were located in areas that were infrequently occupied by Black Sea Bass (Fabrizio et al., 2013). Between 30 May and 14 December 2003, when the last detection was recorded at the site, we obtained 1,252,573 detections. Some of these detections were removed from consideration because they were redundant, occurring at the same time on adjacent receivers. Single detections, which may have resulted from acoustic or environmental interference, and occurrences of less than 5 detections during a 24 -h period were also removed, ${ }^{6}$ as were detections from unknown transmitters. Homerange and seasonal movement analyses were based on the resulting set of $1,007,787$ detections.

\section{Home range of Black Sea Bass during inshore residency}

Home-range size of individual Black Sea Bass varied greatly (13.7-736.4 ha, $n=109$ fish), and fish of unknown sex tended to exhibit the greatest variation in home-range size (Fig. 2). About 95\% of Black Sea Bass of unknown sex used areas $<488.8$ ha (Fig. $2 ; n=78$ ). In contrast, $95 \%$ of males maintained home ranges $<278.7$ ha $(n=31)$, and no males occupied home ranges $>332.4$ ha. On average, fish of unknown sex used 137.2 ha (SE 17.19) home ranges, and males used 120.9 ha (SE 15.29) home ranges. These mean home ranges represent about $2.6 \%$ and $2.2 \%$ of the total area of the HARS. Home ranges of individual fish overlapped.

Home-range size of Black Sea Bass varied by sex and depended on duration of occupancy (significant interaction, $F=4.20, P=0.04)$. Using sex-specific models, we explored the effects of duration of occupancy, fish length, and release date on home ranges of males

\footnotetext{
${ }^{6}$ Pincock, D. G., and F. W. Voegeli. 2002. A quick course in underwater telemetry systems, 31 p. VEMCO Ltd, Bedford, Nova Scotia, Canada.
} 


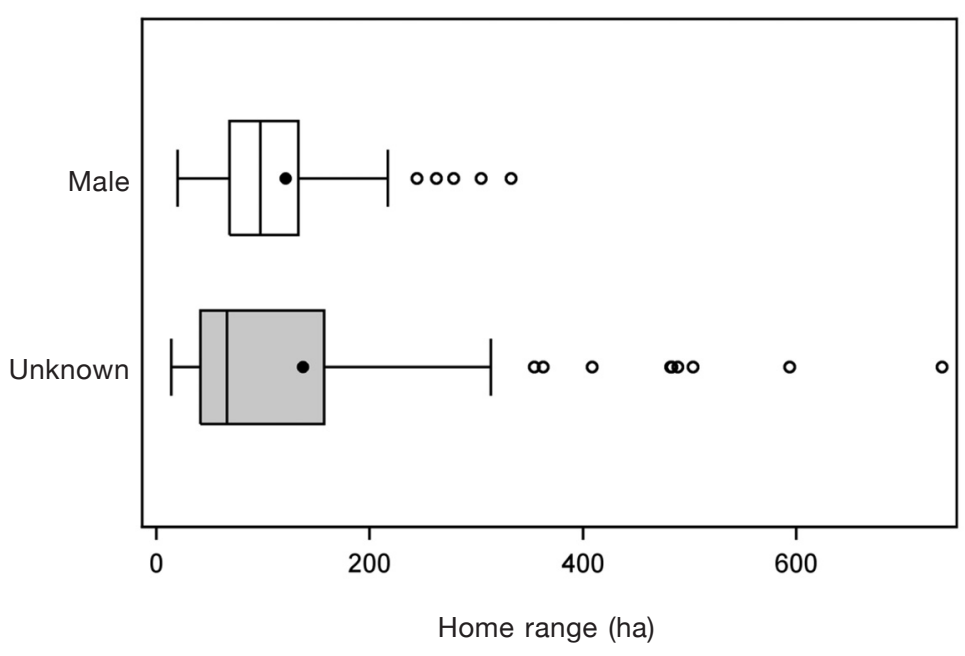

Figure 2

Distribution of home-range size (ha) of 109 Black Sea Bass (Centropristis striata) on the basis of $85 \%$ kernel density estimates for 31 male and 78 fish of unknown sex, a group that included females, immature males, and transitional males. Black Sea Bass were acoustically tagged and released between May and July 2003 at the Historic Area Remediation Site (Fig. 1) in the mid-Atlantic Bight. Mean home-range size is indicated by a filled circle; the vertical edges of the rectangle are the $25^{\text {th }}$ and $75^{\text {th }}$ percentiles; the vertical line inside the rectangle indicates the median; the whiskers extend to 1.5 times the difference between the $25^{\text {th }}$ and $75^{\text {th }}$ percentiles (the interquartile range); and the open circles are observations more extreme than those of the interquartile range.

$n=7$; predicted mean $_{\mathrm{Jul}}=63.0$ ha, $n=11$; Fig. 4). Furthermore, size of male fish did not explain the observed variation in mean home range $(F=0.70, P=0.41)$. Regardless of when male fish were tagged, the average size of these fish was similar ( $F=0.55, P=0.46)$, implying that male body size did not account for the smaller home ranges observed among fish tagged in the latter part of the tagging period.

\section{Movement of Black Sea Bass}

Black Sea Bass were more likely to move in summer than in fall; fish were also more likely to move with increasing mean daily temperature differences at stations B1 and H7. Time period did not affect the probability of movement between adjacent receivers, nor did differences across the study site in mean salinity at the bottom of the seafloor. The best model from the set of models considered was that with an $m$-dependent correlation structure with $m=30$ to model the correlations between observations; 30 time intervals corresponds to 7.5 days indicating that movement probabilities within a given week were significantly correlated, but not thereafter. The interactions retained in the model included cubic time interactions with release group and sex (and all the lower order 2-way interactions contained therein), as well as the interaction

and fish of unknown sex. Duration of occupancy significantly affected the home-range size of fish of unknown sex $(F=14.15, P<0.01)$ but not the home-range size of males $(F=0.01, P=0.91)$. Fish of unknown sex that occupied the site for short periods had significantly larger home ranges than those fish of unknown sex that occupied the site for longer periods $(\delta=-0.010, t=-3.78$, $P<0.01$; Fig. 3). Duration of occupancy was the only factor that significantly affected home-range size of fish of unknown sex; neither fish size $(F=0.81, P=0.37)$ nor release date $(F=0.04, P=0.83)$ was significant in prediction of mean home-range size of these fish. As noted previously, estimates of the duration of occupancy may have been biased low, particularly for fish released later in the tagging period. However, release date did not affect duration of occupancy $(F=0.17, P=0.69)$, indicating the lack of systematic bias in the estimated duration of occupancy for these fish.

In contrast to the results observed for fish of unknown sex, we found a significant effect of release date on home-range area of male fish $(F=5.81, P=0.02)$ such that, on average, males tagged and released in early June established home ranges that were at least twice the size of home ranges established by males tagged and released in July (predicted mean earlyJun $_{\text {end }}$ (43.2 ha, of time with mean temperature at station B1 (Table 1); these complex movement probabilities are therefore described separately for males and fish of unknown sex.

Between June and October, the probability of moving decreased for male fish and was lowest among males released in late June compared with males released at other times (Fig. 5A); between October and mid-November, the probability of moving increased for males released in July but remained low for the males released in late June (Fig. 5A). Males released in early June were no longer present at the site by mid-September; therefore, movement likelihoods could not be estimated for this group. In contrast, fish of unknown sex from all release groups exhibited similar probabilities of movement that decreased between June and November (Fig. 5B); however, fish of unknown sex released in late June maintained higher probabilities of movement between October and mid-November than did fish of unknown sex from other release groups (Fig. 5B). The most pronounced difference among the sexes occurred for the July release group between October and midNovember: among males, those fish released in July exhibited the highest probability of moving during this time period, whereas fish of unknown sex released in July exhibited the lowest probability of movement. 


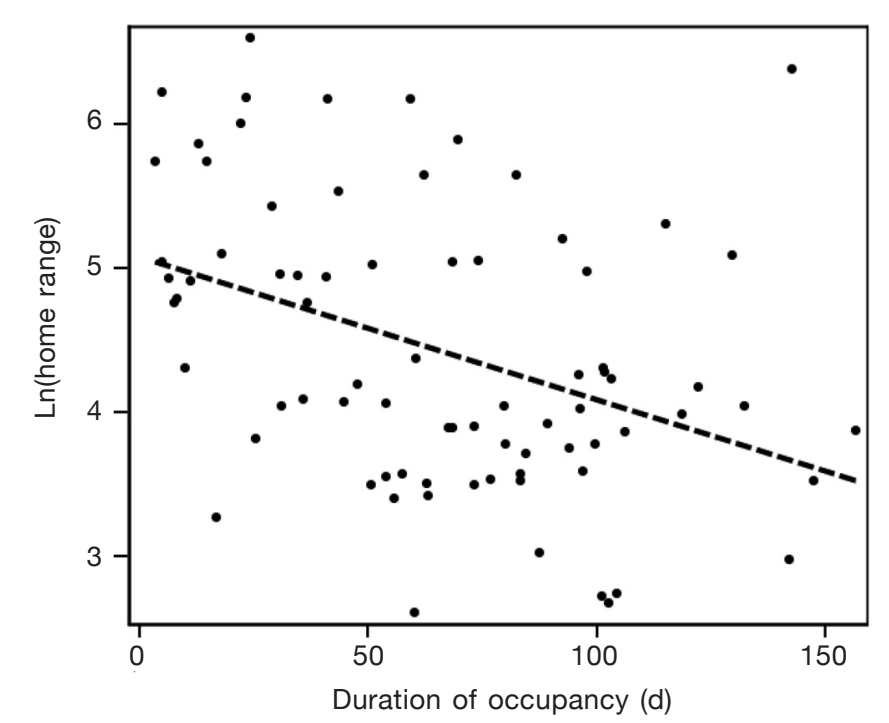

Figure 3

Relationship between $\log _{e}$-transformed home-range size (ha) and duration of occupancy for 78 Black Sea Bass (Centropristis striata) of unknown sex at a reef in the mid-Atlantic Bight during summer-fall 2003; these fish included females, subordinate males, and transitional males. Duration of occupancy was calculated as the difference between release date and date last detected at the study site in 2003; fish were released between 30 May and 16 July 2003. The dashed line is a linear regression line provided for reference only.

Linear changes in the probability of moving varied with water temperature at the bottom of the seafloor at station B1; the linear decline in the likelihood of moving was more rapid at higher water temperatures (i.e., temperatures exceeding $13^{\circ} \mathrm{C}$; Fig. 6). These higher temperatures were observed at the site primarily during September. Generally, average water temperatures in fall exceeded those temperatures observed in summer: mean temperature at the bottom of the seafloor at station $\mathrm{B} 1$ was $15.58^{\circ} \mathrm{C}$ (SE 0.05) in fall and $12.60^{\circ} \mathrm{C}$ $(\mathrm{SE}=0.03)$ in summer.

\section{Activity of Black Sea Bass}

For fish that did move, the random structure of the data for the continuous activity index was best described by including the variation associated with individual fish in the GLMM and by modeling the correlations among observed movements across time periods and days with an autoregressive moving average structure (with lag 1). The difference in AIC between models with and without the random fish factor exceeded 390, indicating that an important portion of the variation in the observed continuous activity index was associated with individual fish. Variation among individuals in activity levels accounted for $22-26 \%$ of the random variation observed during any given time period (Table 2).
As we found when modeling the binomial probability of movement, activity levels of fish measured by the continuous activity index varied with season, time, release group, sex, and water temperature at the bottom of the seafloor at the study site (Table 2). Activity of Black Sea Bass decreased with decreasing differences in mean temperature across the site from summer through fall; however, the remaining main effects could not be interpreted directly because of the presence of multiple 2-way interactions (Table 2). Cubic time effects on activity of Black Sea Bass varied by season and with release group (Fig. 7) such that, during summer, fish released in early June were consistently more active than were fish released in late June or July. The mean predicted activity index exhibited less variation during summer than during fall (Fig. 7); in summer, activity levels seemed fairly constant, until about late August (day 90 in Fig. 7), when activity levels declined rapidly. Subsequently, activity levels of fish were highly variable and depended on release group: fish released in late June were more active in fall than were those fish released earlier or later (Fig. 7).

Activity levels of Black Sea Bass exhibited significant linear and quadratic changes through time in response to mean temperature but these responses differed for males and fish of unknown sex (Fig. 8). Male fish appeared less responsive to temperature than fish of unknown sex, which exhibited decreasing levels of activity with increasing temperature (Fig. 8). The effect of time period on activity of Black Sea Bass was marginal (Table 2), but our modeling results indicate that fish were slightly more active during crepuscular periods and least active during the day. Consistency of the continuous activity index during successive days was greatest at night $(\gamma=0.3297$; Table 2); these responses exhibited higher correlations across time than did responses measured during other time periods.

\section{Discussion}

\section{Home range of Black Seas Bass during inshore residency}

We provide the first estimates of home-range size for Black Sea Bass in the mid-Atlantic during their inshore residency period; individuals maintained large, overlapping home ranges (13.7-736.4 ha), reflecting the spatial extent of feeding and spawning areas. Although fish were detected throughout the study site, most fish used relatively shallow areas of coarse sediments in the central portion of the site (Fabrizio et al., 2013), indicating that the extent of suitable habitat may have restricted home ranges of these fish. Black Sea Bass that inhabit other temperate reefs in the mid-Atlantic region may exhibit larger or smaller home ranges, de- 


\section{Table 1}

Comparison of the fit of the top 14 models of activity for Black Sea Bass (Centropristis striata) at a reef in the mid-Atlantic Bight during the period May-November 2003, with the following 10 predictors included in all models: sex; season; release group ( $\mathrm{rg}$ ); time period (dawn, day, dusk, and night); linear $(t)$, quadratic $\left(t^{2}\right)$ and cubic $\left(t^{3}\right)$ time; mean difference in temperature at stations B1 and H7 (see Fig. 1), 2 of the stations where acoustic receivers were deployed; mean difference in salinity at stations $\mathrm{B} 1$ and $\mathrm{H} 7$; and mean temperature at station B1 (temp). The response was coded 0 (no movement) or 1 (movement) during a given 3-h time period; the subject of each repeated-measures model was individual fish nested in time period. The quasi-likelihood information criterion (QIC) is a modification of Akaike's information criterion appropriate for repeated-measures models of binomial responses.

\begin{tabular}{|c|c|c|}
\hline 10 Predictors + & QIC & $\Delta \mathrm{QIC}$ \\
\hline $\operatorname{sex}^{*} r g+\operatorname{sex}^{*} t^{3}+r g^{*} t^{3}+t e m p^{*} t+\operatorname{sex} * r g^{*} t^{3}$ & 32247.316 & 0.0 \\
\hline $\operatorname{sex} * r g+\operatorname{sex} * t^{2}+r g^{*} t^{2}+t e m p^{*} t^{2}+\operatorname{sex} r g^{*} t^{2}$ & 32265.321 & 18.005 \\
\hline$s e x^{*} r g+\operatorname{sex} t^{3}+r g^{*} t^{3}+t e m p^{*} t^{3}+s e x^{*} r g^{*} t^{3}$ & 32267.646 & 20.330 \\
\hline$s e x^{*} r g+r g * t^{3}+t e m p * t+t e m p * t^{2}$ & 32277.678 & 30.362 \\
\hline$s e{ }^{*} r g+\operatorname{sex} * t^{3}+r g^{*} t^{3}+t e m p^{*} t^{2}+\operatorname{sex} * r g^{*} t^{3}$ & 32278.182 & 30.866 \\
\hline$s e x^{*} r g+\operatorname{sex}^{*} t^{2}+r g^{*} t^{2}+t e m p^{*} t+\operatorname{sex} * r g^{*} t^{2}$ & 32279.667 & 32.351 \\
\hline$s e x^{*} r g+\operatorname{sex}^{*} t^{2}+r g^{*} t^{2}+t e m p^{*} t^{3}+\operatorname{sex} r g^{*} t^{2}$ & 32284.446 & 37.130 \\
\hline$s e x * r g+r g^{*} t^{3}+t e m p * t$ & 32284.549 & 37.233 \\
\hline$s e{ }^{*} r g+r g^{*} t^{2}+r g^{*} t e m p+t e m p * t+t e m p * t^{2}+r g^{*} t e m p^{*} t^{2}$ & 32285.540 & 38.224 \\
\hline$s e x * r g+r g^{*} t^{3}+t e m p * t+t e m p^{*} t^{2}+t e m p^{*} t^{3}$ & 32287.220 & 39.904 \\
\hline$s e{ }^{*} r g+r g * t^{2}+t e m p^{*} t^{2}$ & 32289.342 & 42.026 \\
\hline$s e{ }^{*} r g+r g^{*} t^{2}+r g^{*} t^{3}+t e m p^{*} t+t e m p^{*} t^{2}$ & 32293.091 & 45.775 \\
\hline$s e x * r g+r g^{*} t^{3}+t e m p * t+t e m p^{*} t^{3}$ & 32294.340 & 47.024 \\
\hline$s e{ }^{*} r g+r g^{*} t^{2}+t e m p^{*} t$ & 32298.118 & 50.802 \\
\hline
\end{tabular}

pending on reef size. We hypothesize that the size and spatial distribution of temperate reefs and other hardbottom structures along the Atlantic coast and in the Gulf of Mexico may contribute to observed variation in home-range size within this species.

Home-range sizes reported for other fishes tend to be relatively small ( $<1 \mathrm{ha})$, possibly reflecting the limited spatial and temporal scales over which these types of studies are typically conducted (e.g., Topping et al., 2005; March et al., 2010; Mason and Lowe, 2010). Additionally, fishes that exhibit a high affinity to a particular habitat (e.g., coral reefs) often have relatively small home ranges. Black Sea Bass home ranges were markedly larger than the ones reported for other structure-oriented fishes (e.g., Parrotfish [Sparisoma cretense]: 0.0037 ha, Afonso et al., 2008; Schoolmaster [Lutjanus apodus]: 4.7 ha, Gray Snapper [L. griseus]: 14.6 ha, HammerschlagPeyer and Layman, 2010). Subadult Prickly Shark (Echinorhinus cookei) in Monterey Canyon maintained home ranges similar in size to Black Sea Bass (20-146 ha; Dawson and Starr, 2009), as did several species of coral reef fishes in the Dry Tortugas National Park (144-417 ha; Farmer and Ault, 2011). These observations and those of

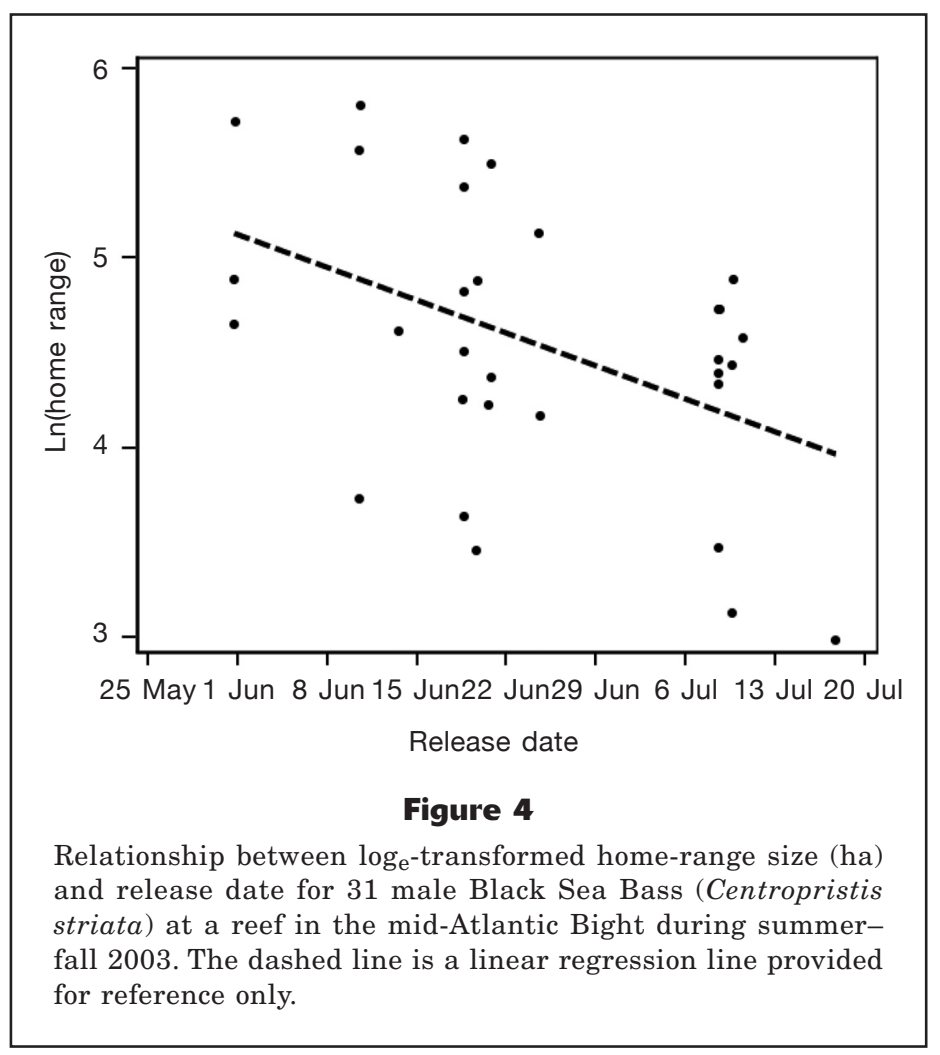



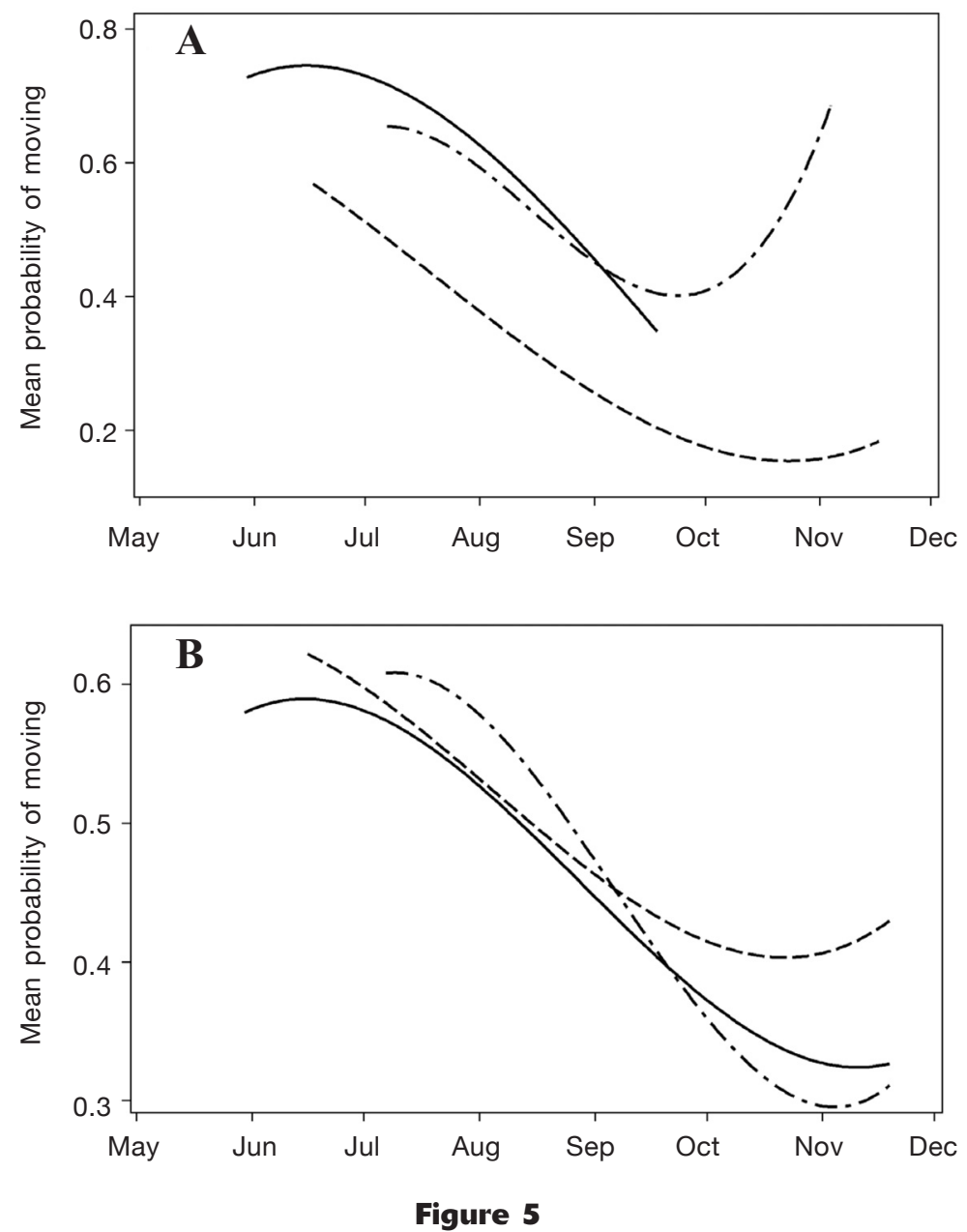

Effect of release group on mean predicted probability of moving for 3 groups of Black Sea Bass (Centropristis striata) tagged and released at a reef in the mid-Atlantic Bight in early June (solid line), late June (dashed line), and July (dotted and dashed line) 2003 for (A) males $(n=34)$ and (B) fish of unknown sex $(n=87)$. Movement was indexed as either 0 (no movement) or 1 (movement) and was observed from 30 May to 19 November 2003; predicted means are from a binomial repeated-measures model.

Farmer and Ault (2011) support our notion that the use of appropriate temporal and spatial domains of study is critical for estimation of home ranges of fishes.

Studies that incorporate large numbers of fish can elucidate the degree of variation in home-range sizes and may be helpful in clarifying habitat use among groups of conspecifics. We found an order of magnitude difference in home-range sizes among 109 Black Sea Bass at our study site (13.7-736.4 ha). However, the magnitude of this variation was not unusual, as Spot-tail Shark (Carcharhinus sorrah) in Australia used areas varying between 1 and 7802 ha as home ranges (Knip et al., 2012), and home ranges of California Sheephead (Semicossyphus pulcher), another pro- togynous hermaphrodite, spanned 2 orders of magnitude (Topping et al., 2005). The large variation in home-range size among Black Sea Bass may reflect the distribution of prey resources at the study site or the extent of competitive interactions among fish for prey and shelter. Population density at the reef also may play a role in structuring space use among conspecifics. Our study was conducted during the inshore residency period of Black Sea Bass in a single year, and, as such, the specific home-range sizes we report here may be indicative of conditions in 2003. However, the relative home-range size and order-of-magnitude variation in home ranges in this population are likely to be independent of year of observation.

Home ranges of adult Black Sea Bass were fish-size invariant. Theory indicates that larger fish may require larger areas for feeding and that larger fish are able to patrol and defend larger areas with less metabolic cost than smaller fish are able to do (Kramer and Chapman, 1999). Although such relationships have been observed in some marine fishes (e.g., Jones, 2007; Taylor et al., 2007; Marshell et al., 2011), others have reported no effect of fish size on homerange size (e.g., Lowe et al., 2003; Afonso et al., 2008; Bellquist et al., 2008; Farmer and Ault, 2011; this study). Apparent inconsistencies with theoretical expectations may arise because the relationship between body size and home-range size applies only to comparisons among species or among life stages of a given species (e.g., Jones, 2007). For example, juvenile Black Sea Bass displayed restricted use of estuarine habitats in New Jersey, rarely moving more than $120 \mathrm{~m}$ (Able and Hales, 1997); this geographic scale of habitat use contrasts markedly with the extent of the area used by adults during their inshore residency (this study) or throughout their life (Moser and Shepherd, 2009). However, within a given life stage of a single species, home range appears to be less affected by fish size.

Home ranges of Black Sea Bass of unknown sex (females, subordinate males, and transitional males) were smaller among individuals with longer inshore residency times, indicating that fish of unknown sex that occupied smaller home ranges ( $<137.2 \mathrm{ha})$ exhibited higher site affinities. These tendencies may reflect the reproductive strategy of females and small males in this group. For example, females that occupied the site for only short periods $(<50 \mathrm{~d})$ may move freely 


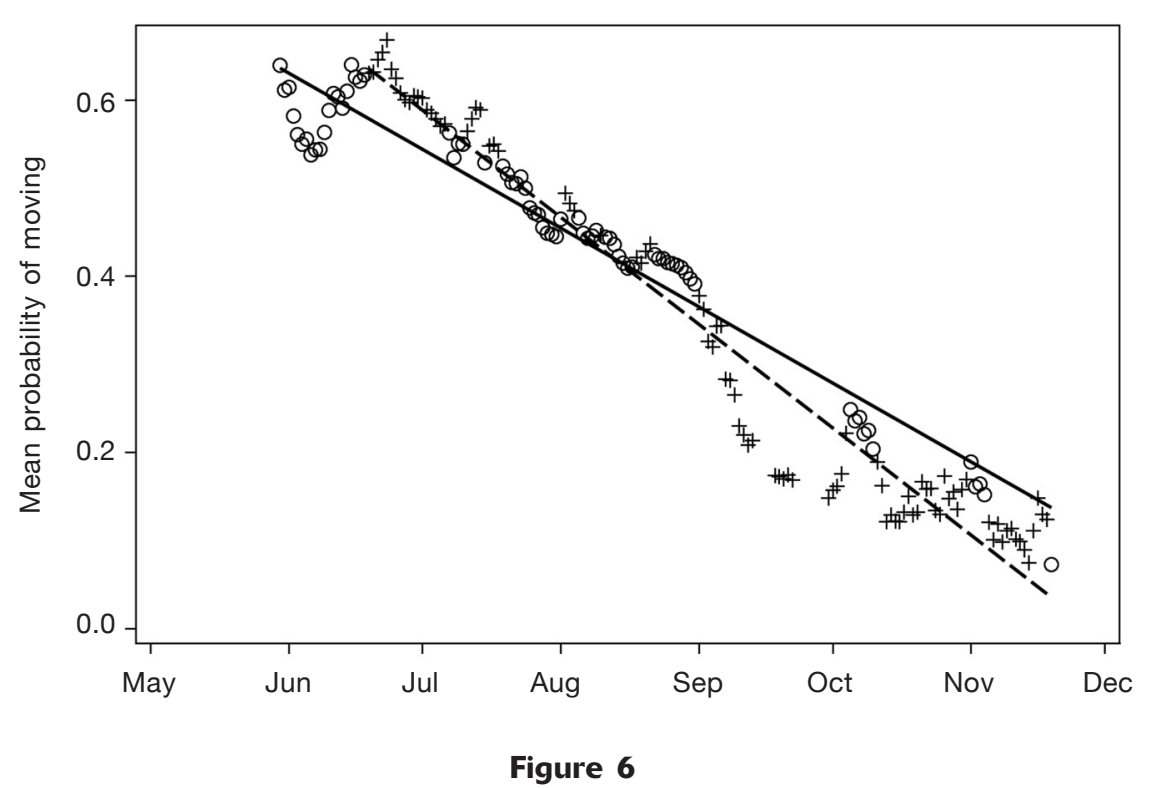

Mean predicted probability of moving for Black Sea Bass (Centropristis striata) at a reef in the mid-Atlantic Bight during periods of low (open circles, solid line) and high (crosses, dashed line) water temperatures at the bottom of the seafloor; temperatures $<13^{\circ} \mathrm{C}$ are low, and those temperatures $>13^{\circ} \mathrm{C}$ are high. Predictions are for 121 Black Sea Bass fitted with acoustic transmitters and tracked between late May and mid-November 2003.

among social groups (and, therefore, exhibited larger home ranges [ $>100$ ha]), but females that occupied the site for longer durations ( $>100 \mathrm{~d}$ ) may have been more strongly associated with a specific group (and, therefore, exhibited smaller home ranges $[<60 \mathrm{ha}])$. The mating system of Black Sea Bass has not been observed in the wild, but on the basis of observations with captive fish (Nelson ${ }^{7}$ ), these social groups are likely to be harems. Some of the fish that exhibited larger home ranges may have been fish undergoing transformation to males (see, e.g., Mercer, 1978). As such, these fish may display exploratory behaviors, searching for territories or joining spawning groups as "sneaker" males. Additional studies on the reproductive strategies and social behavior of this species are needed to understand the mating system of Black Sea Bass and the role of sextransitioning fish.

On average, mature male Black Sea Bass exhibited smaller home ranges than did females and subordinate or transitional males, perhaps, because mature males establish territories only as large as they can successfully patrol and defend. These sex-related differences in home-range size were similarly observed in another protogynous serranid, Pseudanthias squamipinnis (Shapiro, 1987). However, our study and that of Shapiro (1987) contrast with results reported for other ter-

\footnotetext{
${ }^{7}$ Nelson, D. 2005. Personal commun. NOAA Fisheries Service, Northeast Fisheries Science Center, Milford, CT 06460.
}

ritorial protogynous fishes, such as hogfishes (Bodianus spp.), for which home ranges of males exceeded those of females (Hoffman, 1983). The difference we observed for Black Sea Bass may be due to the significantly larger home ranges (13.7-736.4 ha) of fish on inner-shelf habitats compared with those of fish using coral-reef habitats, where home ranges are typically on the order of a few hundred square meters (0.01-0.05 ha; see e.g., Hoffman, 1983).

Furthermore, if we assume that fish tagged and released at a given time represented the population of available fish, then fish released early in the study may have arrived at the site earlier than those fish tagged and released later in the study period. Under this assumption, mature male Black Sea Bass that arrived early at the site (i.e., fish released in early June) established larger home ranges ( $>120$ ha) than males arriving later in summer (fish released in July), indicating that spawning territories may be limited on the inner continental shelf and that late-arriving males may be less likely to establish and maintain larger territories.

The observed relationship between mean size of the home-range area of males and timing of release also was observed among the minimum and maximum size of the home-range area of these fish and the timing of their release. Whether home-range size is related to spawning success of males is unknown, but such knowledge could shed light on the importance of the timing of inshore migrations and the ability of males to 


\section{Table 2}

Estimated parameters from the general linear mixed model of activity level for Black Sea Bass (Centropristis striata) at a reef in the mid-Atlantic Bight during the period May-November 2003, with the activity index $\log _{\mathrm{e}}$ transformed to meet homogeneity of variance assumptions. The model was fitted to 11,843 observations from 121 Black Sea Bass. The additional variance associated with individual fish was 0.1578 ; the correlations among activity levels during dawn, day, dusk, and night were modeled with an autoregressive moving average model with parameters $\sigma^{2}, \rho$, and $\Gamma$, where $\sigma^{2}$ is the estimate of the residual variance for each time period, $\Gamma$ is the estimated correlation between 2 successive repeated measures, $\Gamma \rho$ is the estimated correlation between observations 2 (time) units apart, $\Gamma \rho^{2}$ is the estimated correlation between observations 3 (time) units apart, and so forth. Temp is temperature in degrees Celsius $\left({ }^{\circ} \mathrm{C}\right)$ at the bottom of the seafloor; B1 refers to the acoustic station depicted in Figure 1; time period refers to dawn, day, dusk, and night; df is degrees of freedom.

\begin{tabular}{lcccc}
\hline Covariance parameter & Dawn & Day & Dusk & Night \\
\hline$\sigma^{2}$ & 0.4840 & 0.5548 & 0.4637 & 0.4530 \\
$\rho$ & 0.8351 & 0.8619 & 0.8636 & 0.7622 \\
$\Gamma$ & 0.2332 & 0.2533 & 0.2603 & 0.3297
\end{tabular}

Type-III tests of fixed effects

\begin{tabular}{|c|c|c|c|c|}
\hline Effect & Numerator df & Denominator df & $F$ & $P$ \\
\hline Sex & 1 & 116 & 0.90 & 0.345 \\
\hline Season & 1 & 7062 & 0.38 & 0.536 \\
\hline Release group & 2 & 118 & 1.06 & 0.350 \\
\hline Time period & 3 & 431 & 1.96 & 0.120 \\
\hline Time & 1 & 2829 & 96.88 & $<0.001$ \\
\hline Time $^{2}$ & 1 & 5366 & 8.45 & 0.004 \\
\hline Time $^{3}$ & 1 & 4244 & 47.76 & $<0.001$ \\
\hline Temp difference & 1 & 8431 & 7.23 & 0.007 \\
\hline Temp at B1 & 1 & 5713 & 19.06 & $<0.001$ \\
\hline Salinity difference & 1 & 6163 & 1.54 & 0.215 \\
\hline Temp at $\mathrm{B} 1 *$ time & 1 & 5144 & 9.53 & 0.002 \\
\hline Temp at $\mathrm{B} 1 *$ time $^{2}$ & 1 & 6003 & 22.83 & $<0.001$ \\
\hline Temp at $B 1 *$ sex & 1 & 4797 & 34.06 & $<0.001$ \\
\hline Season*time ${ }^{3}$ & 1 & 5825 & 28.52 & $<0.001$ \\
\hline Release group*time ${ }^{3}$ & 2 & 3809 & 19.67 & $<0.001$ \\
\hline
\end{tabular}

successfully establish territories for reproduction and recruitment.

The observed variations in home-range size among Black Sea Bass have implications for management of these fisheries. In the mid-Atlantic, commercial and recreational fisheries target fish at specific reefs; although the distribution of fishing activity at the reefs is not strictly random, vulnerability to capture is likely to increase with increasing home-range size. The largest home ranges were observed for fish of unknown sex that occupied the site for shorter $(<50 \mathrm{~d})$ periods of time; occupancy duration may have been short because these fish dispersed from the site or because they were harvested or died of natural causes. Males released in early June had home-range areas that were larger than those areas of other males, indicating that groups of males may be differentially vulnerable to capture.
Because reefs may support populations characterized by groups of fish that exhibit differences in space use and activity levels, differential vulnerability of groups may further exacerbate variation in exploitation rates among reefs. In addition, fishery removal of mature males may initiate sex transformation in females (Benton and Berlinsky, 2006), a process that is ensured by social interactions among individuals with overlapping home ranges.

\section{Seasonal movements of Black Sea Bass}

During their inshore residency in the mid-Atlantic Bight, Black Sea Bass were more likely to undertake large-scale movements (>400 m) during summer, when mean cross-shelf differences in water temperature at the bottom of the seafloor were more pronounced than 
in other seasons. Similarly, mean activity levels of Black Sea Bass were highest during summer and declined significantly in the fall, regardless of time of day. Throughout the summer, fish maintained high mean activity levels that were fairly constant.

Seasonal declines in activity of Black Sea Bass also were observed among 14 Black Sea Bass held in captivity from July through December of 2002 in a $121,000-\mathrm{L}$ research aquarium. In these captive fish, aggressive behaviors were highest soon after dominant males established territories in summer, and these behaviors declined over time. ${ }^{8}$ Our field-based observations of lower mean activity indices in the fall are consistent with a decline in aggressive pursuits and establishment of stable territories. Although laboratory and field experiments yielded analogous results, the spatial scales of these studies were vastly different. Additional studies at the scale investigated at the HARS but with the ability to identify specific movement behaviors (e.g., foraging, evasion, searching) are necessary to determine the nature of seasonal changes in activity levels of Black Sea Bass.

Among Black Sea Bass in the mid-Atlantic, the probability of undertaking seasonal movements on the order of $400 \mathrm{~m}$ varied among groups of fish and depended on sex and other factors. For example, on the basis of the binomial movement index, we observed that mature males that remained at the study site after October were more likely to move than were fish of unknown sex that were present at that time. During that time, that group of males may have been more vulnerable to capture by passive fishing gear. Similarly, differences in seasonal movements unrelated to fish size were observed among release groups of male fish (Fig. 5A). On the basis of our observations, we postulate that Black Sea Bass arrive and establish residence at mid-Atlantic reefs throughout the summer; furthermore, groups of fish within these resident populations exhibit diverse seasonal movement patterns. Variations in movement patterns within a population are not likely to be the result of random movements among individuals; instead, such variations have been postulated to represent behavioral differences that may contribute to niche specializations (Hammerschlag-Peyer and Layman, 2010). Further research is necessary to elucidate factors that contribute to the formation and maintenance of behavioral groups in Black Sea Bass, including factors associated with the complex social behaviors exhibited by this species.

${ }^{8}$ Fabrizio, M. C., J. P. Pessutti, J. P. Manderson, A. F. Drohan, and B. A. Phelan. 2005. Use of the Historic Area Remediation Site by black sea bass and summer flounder. Northeast Fish. Sci. Cent. Ref. Doc. 05-06, 95 p. [Available from National Marine Fisheries Service, 166 Water St., Woods Hole, MA 02543-1026.]

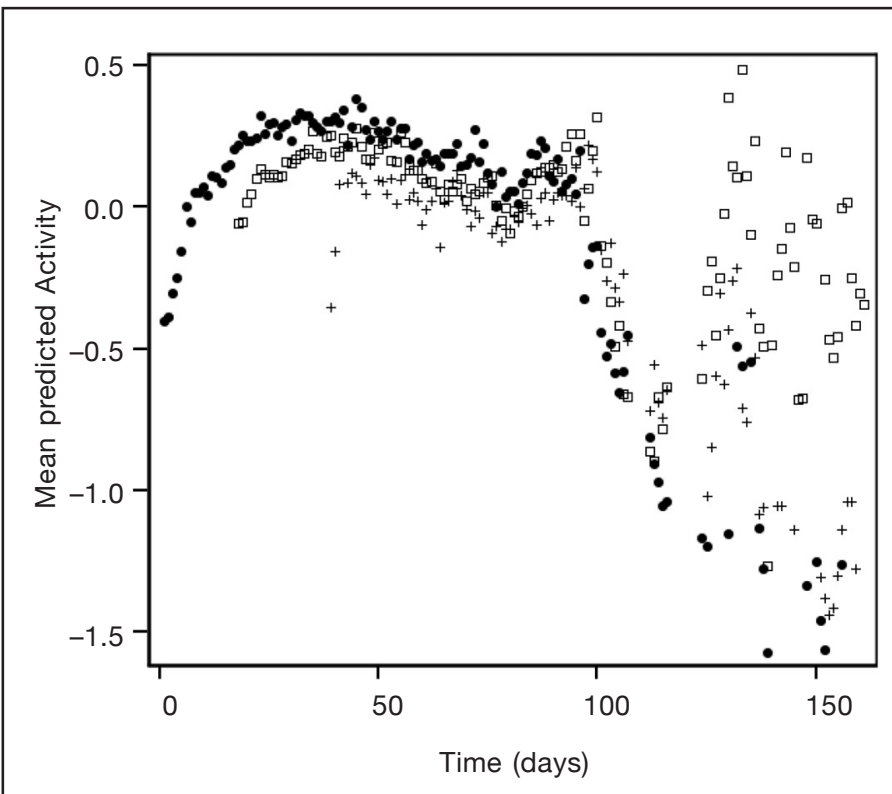

Figure 7

Mean predicted activity levels from the generalized linear mixed model for 3 groups of Black Sea Bass (Centropristis striata) released at a reef in the mid-Atlantic Bight in early June (filled circles), late June (squares), and July (crosses); the activity index is presented in $\log _{e}$-transformed units and the data span the period from 30 May $($ time $=0)$ to 6 November (time=161) 2003.

\section{Diel activity of Black Sea Bass}

In some species, activity patterns are associated with environmental light levels (Løkkeborg et al., 2000) and may be mediated by temperature (e.g., Hurst and Duffy, 2005), nutritional state (Metcalfe et al., 1998), or other factors (Reebs, 2002). We observed declining activity levels (number of times a fish moved $>400 \mathrm{~m}$ during a 3-h period) of Black Sea Bass as temperature differences across the study site decreased. However, individual fish exhibited highly variable activity levels (as measured by the continuous activity index) that were not explained by factors we considered in this study, indicating that age, physiological condition, social status, or other individual-based characteristics mediated activity levels. Additionally, interspecific interactions and the distribution and availability of prey resources likely contributed to observed variations in activity.

Differences in activity levels of Black Sea Bass during crepuscular, daytime, or nighttime periods were less striking than during different seasons. The mean activity index observed during the daytime tended to be lower than mean indices observed during crepuscular periods or at night. Black Sea Bass, which are visual feeders, feed during daylight (Steimle and Figley, 1996), and low activity levels at this time may indicate that fish feeding areas may be located near $(\sim 400 \mathrm{~m})$ areas 


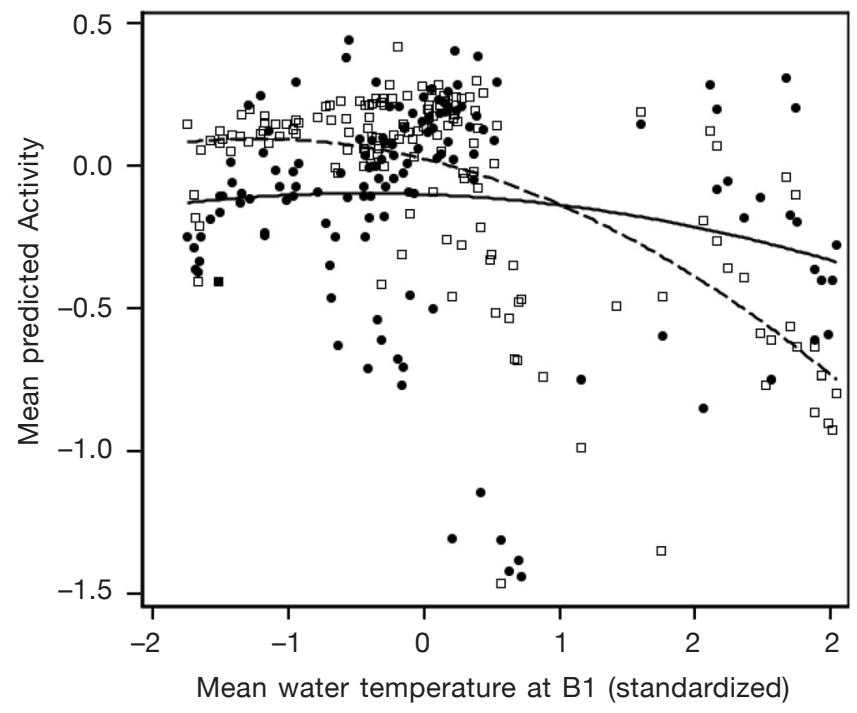

Figure 8

Mean predicted activity levels from the generalized linear mixed model for male Black Sea Bass (Centropristis striata) (filled circles, solid line) and fish of unknown sex (squares, dashed line) at a reef in the mid-Atlantic Bight; the activity index is presented in $\log _{e}$-transformed units. Mean daily water temperature at the bottom of the seafloor was measured in degrees Celsius at acoustic station B1 (see Fig. 1B) from 30 May to 6 November 2003 and was standardized to a mean of 0. Quadratic regression lines are shown for reference only.

frequented by fish during the day and that movements to and from feeding areas are not far ranging. Although adult Black Sea Bass use reefs for shelter, they do not depend exclusively on reef fauna for prey (Steimle and Figley, 1996). In New Jersey coastal waters, Black Sea Bass primarily consume juvenile Atlantic rock crabs (Cancer irroratus) and other invertebrates typically associated with nearby sandy sediments (Steimle and Figley, 1996; Murdy et al., 1997).

Across successive days, we observed greater consistency in mean activity levels at night than during any other time of the diurnal period. Black Sea Bass are believed to spawn at night (McGovern et al., 2002), and, at the study site, movements during night were less variable than movements observed during other times of the day. Consistent nightly activity levels of Black Sea Bass at the study site indicate that if fish spawn at night, spawning may occur near areas used for feeding and shelter. Our acoustic studies of Black Sea Bass movements and activity levels are indicative but cannot address small-scale changes in position associated with complex behaviors and interactions among individuals. For example, social hierarchies may be maintained by dominant males patrolling or defending territories and by females sampling these territories. Other approaches, such as the use of mobile acoustic telemetry or fine-scale acoustic positioning systems, are better suited for investigation of these hypotheses.

\section{Conclusions}

During their inshore residency, Black Sea Bass in the mid-Atlantic region maintained large but highly variable home ranges. Home ranges of females, subordinate males, and individuals transitioning to males depended on the duration of occupancy at the study site, whereas the home range of mature males varied with release group (i.e., groups of fish tagged in early June, late June, or July). Among these mature males, the probability of movement $(>400 \mathrm{~m})$ and mean activity level also varied with release group. Groups of Black Sea Bass exhibited distinct behaviors that may potentially affect growth and reproduction through effects on home-range size. Specifically, mature males released early in the study period may have arrived earlier at the inshore reef and established and maintained larger home ranges than males arriving later in summer. Our acoustic study is the first to indicate the existence of behavioral groups among wild Black Sea Bass. The use of an activity index that gauged movements on the order of $400 \mathrm{~m}$ revealed that Black Sea Bass were most active in summer and activity levels in other seasons were lower and more variable in comparison. Seasonal differences in activity among groups of Black Sea Bass may have resulted in differential vulnerability to exploitation by passive gears, particularly for mature males in fall. Additional studies with large numbers of fish are required to elucidate the composition of behavioral groups and the role of subordinate males, transitional males, and females in the maintenance of group behaviors.

\section{Acknowledgments}

We thank D. Mountain and M. Taylor (NOAA Fisheries, Woods Hole, MA) for loaning us the conductivity, temperature, and depth sensors and providing technical assistance and the NOAA scientists and volunteers who assisted with at-sea operations. Vessel support was provided by S. Sirois (RV Gloria Michelle), R. Haner (RV Gloria Michelle), W. Ihde (MV Samantha Miller), E. Christman (NOAA vessel Thomas Jefferson), C. Brown (RV Nauvoo), J. Hughes (RV Walford), and R. Alix (RV Loosanoff). We thank 2 anonymous reviewers whose suggestions helped clarify the presentation of this work. This study was funded by the U.S. Army Corps of Engineers and was conducted in accordance with guidelines concerning the use of animals in research published by the American Fisheries Society 
and the American Society of Ichthyologists and Herpetologists. M. Fabrizio was partially supported by the Moses D. Nunnally fund. This article is contribution number 3333 of the Virginia Institute of Marine Science, College of William \& Mary.

\section{Literature cited}

Able, K. W., and L. S. Hales Jr.

1997. Movements of juvenile black sea bass Centropris tis striata (Linnaeus) in a southern New Jersey estuary. J. Exp. Mar. Biol. Ecol. 213:153-167.

Afonso, P., J. Fontes, K. N. Holland, and R. S. Santos.

2008. Social status determines behavior and habitat usage in a temperate parrotfish: implications for marine reserve design. Mar. Ecol. Prog. Ser. 359:215-227.

Bellquist, L. F., C. G. Lowe, and J. E. Caselle.

2008. Fine-scale movement patterns, site fidelity, and habitat selection of ocean whitefish (Caulolatilus princeps). Fish. Res. 91:325-335.

Benton, C. B., and D. L. Berlinsky.

2006. Induced sex change in black sea bass. J. Fish Biol. 69:1491-1503.

Bolker, B. M., M. E. Brooks, C. J. Clark, S. W. Geange, J. R.

Poulsen, M. H. H. Stevens, and J.-S. S. White.

2008. Generalized linear mixed models: a practical guide for ecology and evolution. Trends Ecol. Evol. 24:127-135.

Burnham, K. P., and D. R. Anderson.

2002. Model selection and multimodel inference: a practical information-theoretic approach, $2^{\text {nd }}$ ed., $488 \mathrm{p}$. Springer-Verlag, New York.

Calenge, C.

2006. The package "adehabitat" for the R software: a tool for the analysis of space and habitat use by animals. Ecol. Model. 197:516-519.

Clements, S., D. Jepsen, M. Karnowski, and C. B. Schreck.

2005. Optimization of an acoustic telemetry array for detecting transmitter-implanted fish. N. Am. J. Fish. Manage. 25:429-436.

Collette, B., and G. Klein-MacPhee (eds.).

2002. Bigelow and Schroeder's Fishes of the Gulf of Maine, $3^{\text {rd }}$ ed., 748 p. Smithsonian Inst. Press, Washington, D.C.

Collins, M. R., J. C. McGovern, G. R. Sedberry, H. S. Meister, and R. Pardieck.

1999. Swim bladder deflation in black sea bass and vermilion snapper: potential for increasing postrelease survival. N. Am. J. Fish. Manage. 19:828-832.

Dawson, C. L., and R. M. Starr. 2009. Movements of subadult prickly sharks Echinorhinus cookei in the Monterey Canyon. Mar. Ecol. Prog. Ser. 386:253-262.

Douglas, S. G., G. Chaput, J. Hayward, and J. Sheasgreen. 2009. Prespawning, spawning, and postspawning behavior of striped bass in the Miramichi River. Trans. Am. Fish. Soc. 138:121-134.

Fabrizio, M. C., J. P. Manderson, and J. P. Pessutti.

2013. Habitat associations and dispersal of black sea bass from a mid-Atlantic Bight reef. Mar. Ecol. Prog. Ser. 482:241-253.
Fabrizio, M. C., and J. P. Pessutti.

2007. Long-term effects and recovery from surgical implantation of dummy transmitters in two marine fishes. J. Exp. Mar. Biol. Ecol. 351:243-254.

Farmer, N. A., and J. S. Ault.

2011. Grouper and snapper movements and habitat use in Dry Tortugas, Florida. Mar. Ecol. Prog. Ser. 433:169-184.

Hammerschlag-Peyer, C. M., and C. A. Layman.

2010. Intrapopulation variation in habitat use by two abundant coastal fish species. Mar. Ecol. Prog. Ser. 415:211-220.

Hoffman, S. G.

1983. Sex-related foraging behavior in sequentially hermaphroditic hogfishes (Bodianus spp.). Ecology 64:798-808.

Hurst, T. P., and T. A. Duffy.

2005. Activity patterns in northern rock sole are mediated by temperature and feeding history. J. Exp. Mar. Biol. Ecol. 25:201-213.

Jones, K. M. M.

2007. Distribution of behaviours and species interactions within home range contours in five Caribbean reef fish species (Family Labridae). Environ. Biol. Fishes 80:35-49.

Kenward, M. G., and J. H. Roger.

1997. Small sample inference for fixed effects from restricted maximum likelihood. Biometrics 53:983-997.

Knip, D. M., M. R. Heupel, and C. A. Simpfendorfer.

2012. Habitat use and spatial segregation of adult spottail sharks Carcharhinus sorrah in tropical nearshore waters. J. Fish Biol. 80:767-784.

Kramer, D. L., and M. R. Chapman.

1999. Implications of fish home range size and relocation for marine reserve function. Environ. Biol. Fishes 55:65-79.

Lathrop, R. G., M. Cole, N. Senyk, and B. Butman.

2006. Seafloor habitat mapping of the New York Bight incorporating sidescan sonar data. Estuar. Coast. Shelf Sci. 68:221-230.

Liang, K. Y., and S. L. Zeger.

1986. Longitudinal data analysis using generalized linear models. Biometrika 73:13-22.

Limburg, K. E., and J. R. Waldman.

2009. Dramatic declines in North Atlantic diadromous fishes. BioScience 59:955-965.

Littell, R. C., W. W. Stroup, and R. J. Freund.

2002. SAS for linear models, $4^{\text {th }}$ ed., 466 p. SAS Institute Inc, Cary, NC.

Littell, R. C., G. A. Milliken, W. W. Stroup, R. D. Wolfinger, and O. Schnabenberger.

2006. SAS for mixed models, $2^{\text {nd }}$ ed., 814 p. SAS Institute, Inc, Cary, NC.

Løkkeborg, S., K. Skajaa, and A. Fernö.

2000. Food-search strategy in ling (Molva molva L.): crepuscular activity and use of space. J. Exp. Mar. Biol. Ecol. 247:195-208.

Lowe, C. G., D. T. Topping, D. P. Cartamil, and Y. P. Papastamatiou.

2003. Movement patterns, home range, and habitat utilization of adult kelp bass Paralabrax clathratus in a temperate no-take marine reserve. Mar. Ecol. Prog. Ser. 256:205-216.

Mason, T. J., and C. G. Lowe.

2010. Home range, habitat use, and site fidelity of 
barred sand bass within a southern California marine protected area. Fish. Res. 106:93-101.

March, D., M. Palmer, J. Alos, A. Grau, and F. Cardona.

2010. Short-term residence, home range size and diel patterns of the painted comber Serrranus scriba in a temperate marine reserve. Mar. Ecol. Prog. Ser. 400:195-206.

Marshell, A., J. S. Mills, K. L. Rhodes, and J. McIlwain.

2011. Passive acoustic telemetry reveals highly variable home range and movement patterns among unicornfish within a marine reserve. Coral Reefs 30:631-642.

McGovern, J. C., M. R. Collins, O. Pashuk, and H. S. Meister. 2002. Temporal and spatial differences in life history parameters of black sea bass in the southeastern United States. N. Am. J. Fish. Manage. 22:1151-1163.

Mercer, L. P.

1978. The reproductive biology and population dynamics of black sea bass, Centropristis striata. Ph.D. diss., 196 p. Virginia Inst. Marine Science, College of William \& Mary, Gloucester Point, VA.

Metcalfe, N. B., N. H. C. Fraser, and M. D. Burns.

1998. State-dependent shifts between nocturnal and diurnal activity in salmon. Proc. R. Soc. Lond., Ser. B: Biol. Sci. 265:1503-1507.

Meyer, C. G., T. B. Clark, Y. P. Papastamatiou, N. M. Whitney, and K. N. Holland.

2009. Long-term movement patterns of tiger sharks Galeocerdo cuvier in Hawaii. Mar. Ecol. Prog. Ser. 381:223-235.

Moffitt, E. A., L. W. Botsford, D. M. Kaplan, and M. R. O'Farrell. 2009. Marine reserve networks for species that move within a home range. Ecol. Appl. 19:1835-1847.

Moser, J., and G. R. Shepherd.

2009. Seasonal distribution and movement of black sea bass (Centropristis striata) in the Northwest Atlantic as determined from a mark-recapture experiment. J. Northwest Atl. Fish. Sci. 40:17-28.

Murawski, S. A., R. Brown, H.-L. Lai, P. J. Rago, and L.

Hendrickson.

2000. Large-scale closed areas as a fishery management tool in temperate marine systems: the Georges Bank experience. Bull. Mar. Sci. 66:775-798.

Murdy, E. O., R. S. Birdsong, and J. A. Musick. 1997. Fishes of Chesapeake Bay, 324 p. Smithsonian Inst. Press, Washington, D.C.

Musick, J. A., and L. P. Mercer.

1977. Seasonal distribution of black sea bass, Centropristis striata, in the Mid-Atlantic Bight with comments on the ecology and fisheries of the species. Trans. Am. Fish. Soc. 106:12-25.
Neufeld, M. D., and C. R. Spence.

2004. Evaluation of a simple decompression procedure to reduce decompression trauma in trap-caught burbot. Trans. Am. Fish. Soc. 133:1260-1263.

Pan, W.

2004. Akaike's information criterion in generalized estimating equations. Biometrics 57:120-125.

Quinn, G. P., and M. J. Keough.

2002. Experimental design and data analysis for biologists, 537 p. Cambridge Univ. Press, New York.

R Development Core Team.

2005. R. a language and environment for statistical computing. R Foundation for Statistical Computing, Vienna, Austria. [Available from http://www.r-project. org.]

Reebs, S. G.

2002. Plasticity of diel and circadian activity rhythms in fishes. Rev. Fish Biol. Fish. 12:349-371.

Shapiro, D.

1987. Patterns of space use common to widely different types of social groupings of a coral reef fish. Environ. Biol. Fishes 18:183-194.

Shepherd, G. R., and M. Terceiro.

1994. The summer flounder, scup and black sea bass fishery of the Middle Atlantic Bight and Southern New England waters. NOAA Tech. Rep. NMFS 122, 13 p.

Steimle, F. W., and W. Figley.

1996. The importance of artificial reef epifauna to black sea bass diets in the Middle Atlantic Bight. N. Am. J. Fish. Manage. 16:433-439.

Steimle, F. W., and C. Zetlin.

2000. Reef habitats in the middle Atlantic Bight: abundance, distribution, associated biological communities, and fishery resource use. Mar. Fish. Rev. 62:24-42.

Taylor, M. W., S. D. Laffan, D. S. Fielder, and I. M. Suthers. 2007. Key habitat and home range of mulloway Argyrosomus japonicus in a southeast Australian estuary: finding the estuarine niche to optimise stocking. Mar. Ecol. Prog. Ser. 328:237-247.

Topping, D. T., C. G. Lowe, and J. E. Caselle.

2005. Home range and habitat utilization of adult California sheephead, Semicossyphus pulcher (Labridae), in a temperate no-take marine reserve. Mar. Biol. 147:301-311.

Worton, B. J.

1989. Kernel methods for estimation the utilization distribution in home-range studies. Ecology 70:164-168.

Zuur, A., E. N. Leno, and G. M. Smith.

2007. Analysing ecological data, 672 p. Springer, New York. 